\title{
Switching cloud cover and dynamical regimes from open to closed Benard cells in response to the suppression of precipitation by aerosols
}

\author{
D. Rosenfeld ${ }^{1}$, Y. J. Kaufman ${ }^{2, \dagger}$, and I. Koren ${ }^{3}$ \\ ${ }^{1}$ Institute of Earth Sciences, The Hebrew University, Jerusalem 91904, Israel \\ ${ }^{2}$ NASA/Goddard Space Flight Center Greenbelt, MD 20771, USA \\ ${ }^{3}$ Department of Environmental Sciences, Weizmann Institute, Rehovot 76100, Israel \\ $\dagger$ deceased \\ Received: 7 November 2005 - Published in Atmos. Chem. Phys. Discuss.: 10 February 2006 \\ Revised: 20 April 2006 - Accepted: 9 May 2006 - Published: 29 June 2006
}

\begin{abstract}
The dynamic structure of the weakly sheared atmospheric marine boundary layer (MBL) supports three distinct states of cloud cover, which are associated with the concentrations of cloud condensation nuclei (CCN) aerosols in the MBL: (i) CCN rich MBL with closed Benard cellular convection that forms nearly full cloud cover; (ii) $\mathrm{CCN}$ depleted MBL with open cellular convection that forms $<40 \%$ cloud cover; and, (iii) CCN starved MBL where clouds cannot form due to insufficient $\mathrm{CCN}$, with near zero cloud cover. Here we propose a mechanism for the transition between these three states that involves the aerosol impacts on precipitation and the feedbacks on the dynamics of the clouds and on the aerosols deposition. By suppressing precipitation aerosols can reverse the direction of the airflow, converting the cloud structure from open to closed cells and more than doubling the cloud cover. The three states possess positive feedbacks for self maintenance, so that small changes of the conditions can lead to bifurcation of the MBL cloud regime. The transition between the closed and open cells occur at near pristine background level of aerosols, creating a large sensitivity of cloud radiative forcing to very small changes in aerosols at the MBL. The third state of super clean air can occur as the more efficient precipitation in cleaner air deposits the aerosols ever faster in a runaway positive feedback process. The proposed mechanism suggests that very small changes in the aerosols input to the MBL can have large impacts on the oceanic cloud cover and likely in turn on the global temperature, in ways that are not yet accounted for in the climate models.
\end{abstract}

1 Brief review of the effects of aerosols on the cover of marine stratocumulus clouds

Until recently most of the attention in the area of cloudaerosol interactions has been focused on the effects of aerosols producing greater concentrations of smaller drops for a given vertically integrated cloud liquid water path (LWP). This increases cloud albedo, resulting in more incoming radiation being reflected back to space, producing a cooling effect that balances some of the global warming induced by greenhouse gases (Twomey, 1977). Other effects related to the impacts of aerosols on precipitation were also recognized. As early as 1957 it was suggested by Gunn and Phillips (1957), based on cloud chamber experiments, that "the presence of large numbers of contaminating particles in the lower atmosphere acts to generate clouds that do not precipitate but persist in the atmosphere until they re-evaporate. Thus, cloudiness rather than rainfall is characteristic of saturated and highly polluted air masses." Indeed, recent satellite observations of aerosols and shallow clouds' albedo and cover (Sekiguchi et al., 2003; Kaufman et al., 2005) have revealed that the radiative forcing at the top of the atmosphere due to increased cloud fractional cover (CF) and increased LWP produce much more cooling than the Twomey effect (Twomey, 1977). Therefore, it was expected that there would be a monotonic relationship of increasing $\mathrm{N}$ (aerosols concentration) with increasing LWP and CF. Although the first studies of ship tracks (Coakley et al., 1987) confirmed these relationships, more recent and extensive satellite observations showed little relation between N and LWP of the clouds in the ship tracks and adjacent undisturbed clouds (Platnick et al., 2000; Coakley, 2002).

Correspondence to: D. Rosenfeld

(daniel.rosenfeld@huji.huji.ac.il)

Published by Copernicus GmbH on behalf of the European Geosciences Union. 


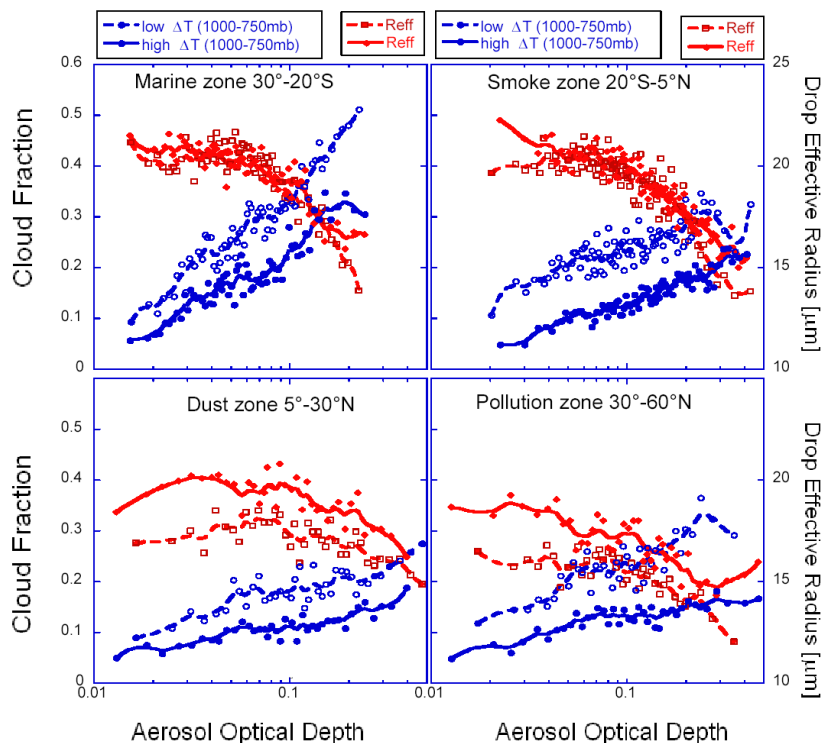

Fig. 1. Cloud cover fraction (CF, blue lines with circles) and drop effective radius (DER, denoted as $R_{\text {eff }}$, red lines with rhombs) of shallow clouds as a function of aerosol optical depth (AOD) for 4 zones over the Atlantic Ocean during August 2002, as defined by Kaufman et al. (2005). The clouds were separated based on stability. Greater stability, which is indicated by smaller $\Delta T(1000$ $750 \mathrm{mb}$ ) and denoted by the broken lines, promotes greater shallow cloud cover. Greater stability also produces shallower clouds with smaller DER for the same AOD. Remarkably, the CF increases with AOD at least as much as with stability. Note that the DER increases and the CF decreases as the AOD decreases, most clearly in the pristine subtropical latitudes of the south Atlantic, supporting the runaway rainout effect of clouds and aerosols.

The apparent complex relations between N, CF and LWP can be appreciated based on the following brief review of the marine stratocumulus cloud processes. Marine stratocumulus clouds are maintained by radiative cooling at their tops, which causes an inverse convection of the cooled air parcels near cloud tops. The evaporation of cloud water into the descending air parcels allows them to descend following a moist adiabat and penetrate deep into the MBL. The apparent lack of dependence of CF and LWP on N in these clouds can be explained by a mechanism in which the loss of cloud water to drizzle would be balanced to some extent by the fact that reduced cloud water allows weaker moist inverse convection and hence less drying due to entrainment of air from the free troposphere (FT) above the cloud tops. Conversely, additional cloud water enhances entrainment by additional evaporative cooling of the moist inverse convection that is driven by the radiative cooling at the top of the cloud covered marine boundary layer (Randall, 1980a; Ackerman et al., 2004). This balance between cloud water and the amount of entrainment can work only up to the point where drizzle is strong enough to actually reach the surface at a greater rate than surface evaporation, drying the MBL even more than the lack of drizzle would dry the MBL through enhanced mixing with the dry FT above (Randall, 1980a; Ackerman et al., 2004).

The onset of intense drizzle occurs when the air becomes sufficiently clean, or when the clouds become sufficiently deep (Gerber, 1996; VanZanten et al., 2005). Ackerman et al. (1993) and later Hegg (1999), using a 1-D model, calculated that if the rain-out of $\mathrm{CCN}$ via collision-coalescence is sufficiently rapid to exceed the source strength of $\mathrm{CCN}$ in the boundary layer, the cleansing of the air will eventually lead to a dissipation of a stratocumulus layer by its raining out. In fact, this is a runaway process with a positive feedback, because for fewer $\mathrm{CCN}$ the coalescence and rainout become more efficient and rapid. In their simulations the cloud droplet number concentration $(\mathrm{N})$ decreased very slowly until reaching $30-40 \mathrm{~cm}^{-3}$, and then dropped sharply to about $4 \mathrm{~cm}^{-3}$. The point of sharp decrease is the point where cloud drops are depleted to the point where they grow diffusionally to the threshold of drizzle size, in agreement with the criteria of Gerber (1996). The onset of this runaway cleansing and clearing occurs after 1 to 5 days, depending on the model initial values (Ackerman et al., 1993). This runaway effect is a basis for a situation of bistability (Baker and Charlson, 1990; Gerber, 1996), where once the atmosphere has reached a very clean situation the highly efficient rainout mechanisms will keep it clean until it will be overwhelmed by a strong source such as smoke from ship stacks or anthropogenic emissions over land. In addition, there is a positive feedback mechanism that prevents replenishing the $\mathrm{CCN}$ in the cleansed MBL from the FT. Most of the mixing with the FT takes place by the mechanism of inverse moist convection into the clouds, which is stronger with larger $\mathrm{CF}$ and greater LWP. Therefore, the decreased LWP, CCN and cloud cover reduce the entrainment of FT air into the MBL (Randall, 1980b; Stevens et al., 2005), and with that also reduce the replenishment of CCN from above (Jiang et al., 2002). This further reinforces a bistability of two cloud cover regimes, one with high CCN and suppressed precipitation and large $\mathrm{CF}$, and the other with drizzle, which cleans the MBL and leads to a positive feedback producing further scavenging of the CCN, enhanced drizzle and ultimately little cloud cover.

Cloud simulations of Baker and Charlson (1990) suggested that this bistability of cloud cover is coupled with CCN concentrations. However, Ackerman et al. (1994), using more advanced cloud simulations, showed that there is a more gradual transition from the low cloud cover and CCN regime to the high cloud cover and $\mathrm{CCN}$ regime. Apparently the bistability of cloud cover and CCN does occur in nature, as evidenced by the sharp transitions between the two cloud cover and drizzle regimes that is associated with respective changes in the aerosols (Stevens, 2005). This means that the onset of heavy drizzle and scavenging of $\mathrm{CCN}$ that were considered by Baker and Charlson (1990) and Ackerman et al. (1994) needs to be complemented by some other not yet identified processes to explain the bistability. This 


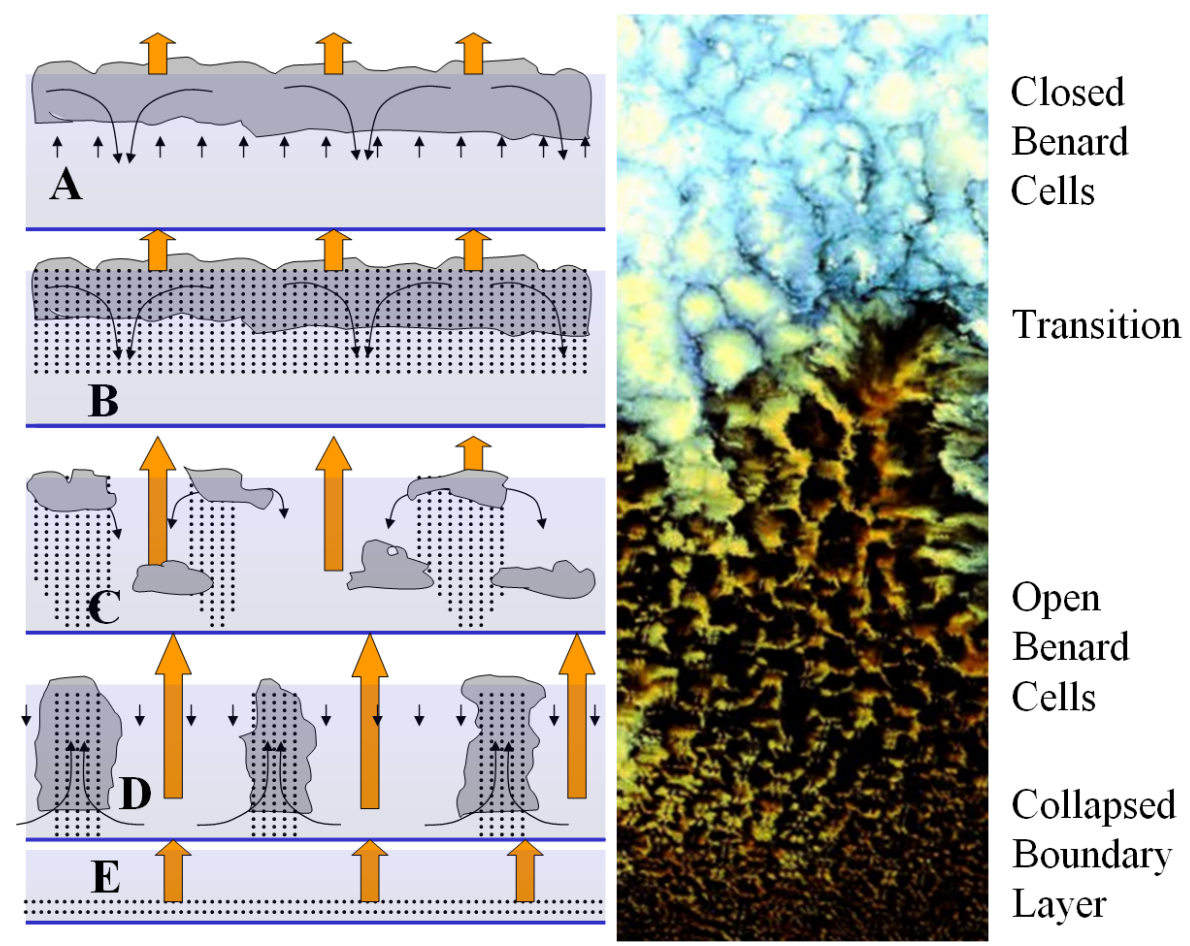

Fig. 2. A schematic illustration of the proposed mechanism for transition from non precipitating closed Benard cells to precipitating open cells and onward to nearly complete rainout and elimination of the clouds. The wide orange arrows symbolize the radiative fluxes. The air motions are represented by the thin black arrows. The drizzle is marked by dots. In the closed Benard cells (a) the convection is propelled by radiative cooling from the tops of the extensive deck of clouds with small drops. The onset of drizzle depletes the water from the cloud deck and cools the sub-cloud layer (b). This leads to decoupling of the cloud cover and to its subsequent breaking (c). The propulsion of the convection undergoes transition from radiative cooling at the top of the fully cloudy MBL (orange arrows in B) to surface heating at the bottom of the partly cloudy MBL causes a reversal of the convection from closed to open Benard cells (d). The process can continue to a runaway effect of cleansing by the $\mathrm{CCN}$ and direct condensation into drizzle that directly precipitates and prevents the cloud formation altogether (e). The satellite strip is a $300 \mathrm{~km}$ long excerpt from the box in Fig. 3.

was recognized by Wood and Hartmann (2006), who documented a climatological average $\mathrm{CF}$ of open and closed Benard cells of 0.5 and 0.9 , respectively. They wrote that "lack of sensitivity of the cellular convection type (open or closed) to the large scale meteorology suggest that a mechanism internal to the MBL may be important in determining the cellular convection type, by a mechanism yet to be determined". Petters et al. (2006) suggested that this mechanism is connected to the aerosols. They stated that "the low accumulation mode concentrations associated with the pockets (of open cellular convection) are proposed to be necessary for their maintenance". But Petters et al. (2006) also stated: "Although we are confident that scarcity of cloud condensation nuclei maintain the pockets, the mechanism itself is not clear."

We suggest that the missing mechanism is a dynamic response of the MBL to the aerosol impacts on cloud microstructure, precipitation and vertical energy fluxes. Section 3 provides the detail of this new hypothesis.

\section{Hitherto unexplained sensitivities of the cloud cover}

In this paper we consolidate the accumulated knowledge above with new observations and analyses (Fig. 1) to point to a new proposed paradigm (Fig. 2) of the aerosol effect on marine stratocumulus $\mathrm{CF}$ that affects the transitions from closed to open Benard cellular convective regimes and further to the cloud-free $\mathrm{CCN}$-starved regime.

Kaufman et al. (2005) used the MODIS (MODerate resolution Imaging Spectroradiometer) data on the Terra satellite to measure the daily aerosol column concentration and its correlation to the local stratiform and trade cumulus cloud cover and properties. MODIS observes detailed aerosol and cloud properties with resolution of $0.5-1 \mathrm{~km}$. Kaufman et al. (2005) summarized the data for all of June-August 2002 into a daily $1^{\circ} \times 1^{\circ}$ latitude and longitude grid. Simultaneous observations of aerosols in cloud-free regions within a $1^{\circ} \times 1^{\circ}$ grid box and observations of cloud properties in the cloudy regions of the same grid box are possible. These simultaneous observations of aerosols and cloud properties were related to each other at Fig. 1. The CF and cloud droplet 
effective radius, DER, are sorted with AOD (aerosol optical depth) and averaged in groups of 50 points of $1 \times 1$ degree, similar to Kaufman et al. (2005). Figure 1 shows that CF increases with AOD while DER decreases with increasing AOD. This provides observational support for the aerosols enhancing CF by reducing DER and suppressing precipitation.

In addition, the respective roles of thermodynamics and aerosols were investigated. The meteorological fields were obtained from the NCEP (National Center for Environmental Prediction) data. The difference in air temperature between 1000 and $750 \mathrm{mb}(\Delta T)$ was found to be the best correlated parameter with the shallow (up to tops of $910 \mathrm{mb}$ ) cloud fraction $(r=-0.35)$, because lower $\Delta T$ indicates a stronger temperature inversion, which caps more extensive marine stratocumulus cloud cover.

The data in Fig. 1 were separated for the lowest and highest $1 / 3$ of $\Delta T$, so that the figure shows the sensitivity of shallow cloud CF to AOD as a function of the atmospheric instability $(\Delta T)$. This analysis shows the remarkable observation that CF depends on AOD to an equal or greater extent than on the lower tropospheric instability, in agreement with the statement of Wood and Hartmann (2006) that is quoted here at the ending of Sect. 1. Figure 1 also supports the suggestion of a runaway cleansing effect of $\mathrm{CCN}$, as manifested by the strong decrease of CF that is associated with AOD decreasing from 0.10 to 0.02 . The decreasing of DER with increasing AOD supports the physical link between CF and AOD. The repeated observations in the very different dynamic and aerosol regimes, as indicated in the four panels of Fig. 1, indicate that the strong decrease of $\mathrm{CF}$ with decreases in $\mathrm{AOD}$ is an inherent process that manifests itself in a wide range of meteorological and aerosol regimes.

\section{A proposed mechanism to the way by which aerosols close open Benard cells}

Boundary layer clouds in a weakly sheared environment occur in two main modes: open and closed cellular convection. Other types of convection such as rolls of cloud streets develop in highly sheared conditions, which are not very common in areas dominated by marine stratocumulus. According to Fig. 14 of Wood and Hartmann (2006) the combined open and closed cellular convection dominate the tropical and subtropical east Pacific. Open cellular convection occurs when the convection is driven mainly by surface heating that causes the air to rise in the cell walls and have a compensating sinking in the middle of the cells. Closed Benard cells occur when instead of surface heating the main driver of the convection is radiative cooling at the cloud tops and gravitational sinking of the cooled air along the walls of the cells, compensated by rising air in the middle of the cells (Agee et al., 1973; Atkinson and Zhang, 1996). Closed Benard cells can be maintained because most of the area is occupied by clouds formed by the slow compensating rising motion, and these clouds provide the radiative cooling from the top that is necessary for maintaining the circulation of closed Benard cells. This closed cellular convection is the typical regime for the lightly or non-drizzling, radiatively-cooled, driven boundary layer clouds (Fig. 2a). The development of drizzle can, in addition to depleting the water from the cloud layer, cool the lower layers, enhance the heat flux from the sea surface into the bottom of the MBL and stabilize the cloudy layer above (Paluch and Lenschow, 1991). This leads to decoupling the upper cloud deck from the lower MBL and hence from replenishing moisture from the sea surface, so that entrainment and drizzling can lead eventually to loss of cloud water and breakup (Fig. 2b). Under sufficiently low CCN conditions the clouds would lose water and clear to the extent that radiative cooling would no longer be strongest at the top of the MBL, but rather come mainly from the water vapor deeper in the MBL, so that radiative cooling would come from deeper in the MBL. This radiative cooling of the lower MBL, along with the evaporative cooling from the drizzle that caused the decoupling in the first place, enhance the MBL sensible and latent heating from the sea surface below at the expense of the radiative cooling flux at the top of the MBL (Randall, 1980b) (Fig. 2c). It is proposed here that eventually the reversal of the direction that drives the convection results in respective reversal of the convection from a regime of closed to open Benard cells (Fig. 2d), so that small convective clouds replace the previous full stratiform cloud cover. The updrafts in the convective elements of the open cells are likely greater than in the stratiform clouds of the closed cells. This leads to stronger drizzle for the same CCN concentrations, because the drizzle drops remain in the updrafts longer and collect a greater number of other cloud drops (Feingold et al., 1996). We propose this as a hypothesis for a mechanism by which reduction of $\mathrm{CCN}$ below a certain threshold can lead to a regime change from closed to open Benard cells with a dramatic decrease in the modal cloud cover fraction from near unity to about 0.25 in the example in Figs. 2-4.

This hypothesized mechanism is supported by observations showing that the transition from closed to open cells is associated with the onset of heavy drizzle and the depletion of the aerosols (Stevens et al., 2005; Petters et al., 2006). Furthermore, we propose here that the runaway effect of the depletion of $\mathrm{CCN}$ can lead to the near complete clearing of the clouds, as shown in Fig. 2e. Such areas where clouds fail to form due to lack of sufficient $\mathrm{CCN}$ can be recognized by the occurrence of conspicuously visible ship tracks in otherwise cloud free areas. Simulations have shown that more strongly drizzling clouds become shallower (Pincus and Baker, 1994), but the observations suggest that this continues until the clouds are nearly eliminated altogether with the runaway effect of scavenging of the $\mathrm{CCN}$ to concentrations of few $\mathrm{cm}^{-3}$, as proposed by Ackerman et al. (1993).

An example to the suggested role of aerosols in the regime transitions from closed to open cells and then to a complete 


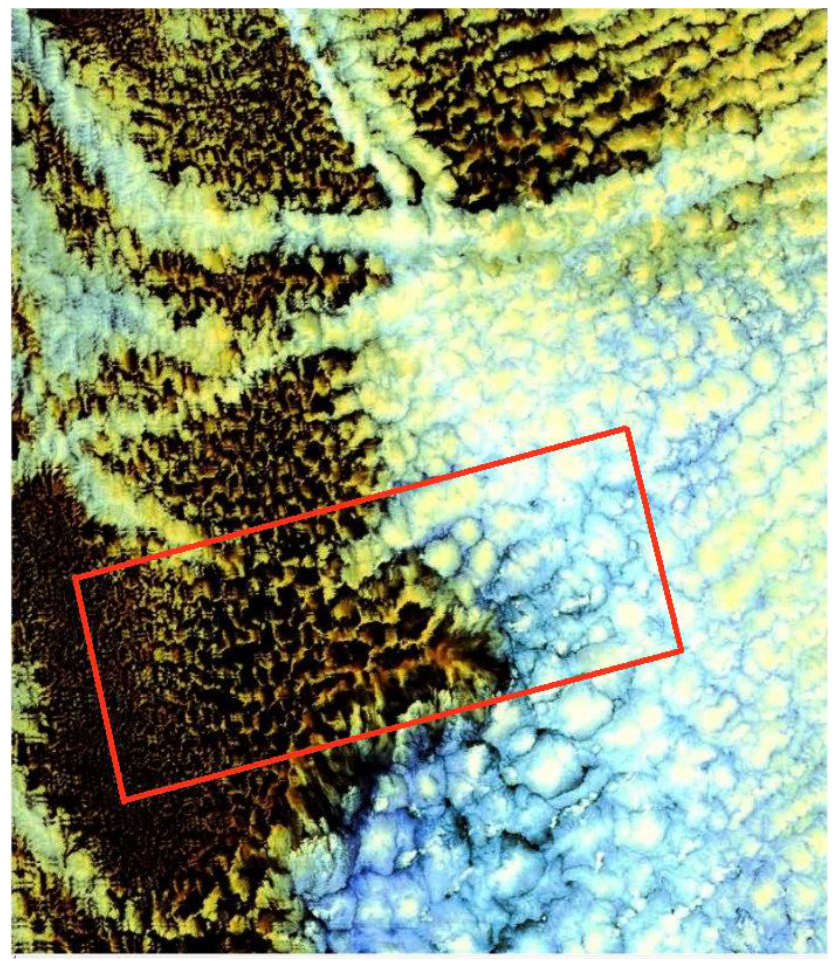

Fig. 3. MODIS image of the relation between microstructure and dynamics of marine stratocumulus in an area of about 400x400 km to the west of the coast of California on 26 June 2003 19:40 UT. The MODIS image is of $500 \mathrm{~m}$ resolution, with color composite of red, green and blue modulating 469, 1640 and $2130 \mathrm{~nm}$ channels, respectively, with Gamma enhancement of 0.2. In this color combination small drops appear bluish, and become red when they become larger. Note the transition from closed to open Benard cells with the increase of drop size, as indicated by changing cloud color to orange and red. The box delimits the area shown in Fig. 2. The drops in ship tracks remain small, and reside in the regime of closed cells. It is clearly seen that the clouds with small drops are brighter and with much greater fractional area coverage than the clouds composed of the larger drops.

runaway rainout effect is evident in Figs. 3 and 4, where old ship tracks occur at the regime of closed Benard cells with small cloud drops extending into areas of open Benard cells in clouds having large effective droplet radii, and then continuing into the cloud-free areas. We rely here on the assumptions that ship tracks are areas with enhanced aerosols concentrations with respect the background, and that the differences in the aerosols concentrations are reflected in the indicated retrieved effective radius of the cloud drops (DER), were smaller drops indicate larger $\mathrm{CCN}$ concentrations.

In this example the DER in the closed cells (Fig. 4) is smaller than the heavy drizzle threshold of $15 \mu \mathrm{m}$ (Gerber, 1996), whereas the DER is considerably larger than $15 \mu \mathrm{m}$ in the open cells. Ship tracks that occur in the area of closed cells are distinguished just by the reduced DER with respect to the already low DER background, without any additional

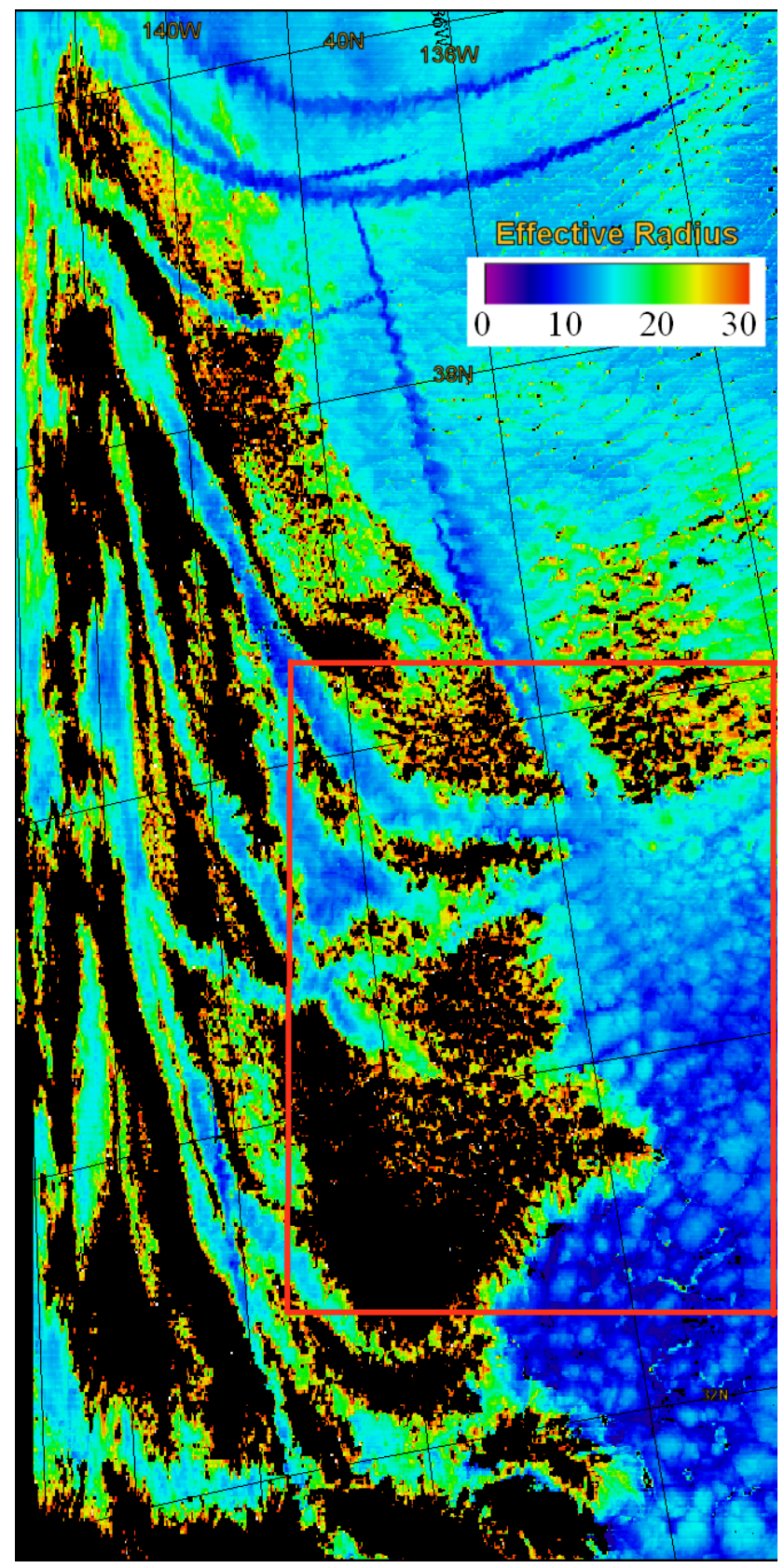

Fig. 4. Same MODIS image as in Fig. 3, but for the MODIS product of effective radius at $1-\mathrm{km}$ resolution over a larger domain. The area of Fig. 3 is bounded by the center right rectangle. Note that the transition from small to large cloud drop effective radius occurs between the solid and broken clouds. Note that ship tracks are maintained in the cloud free areas where runaway rainout and cleansing of the CCN probably occurred.

observable change in the structure of the clouds. The same ship tracks that extend to the area of the open cells maintain their dynamic structure of closed cells and the small DER $<15 \mu \mathrm{m}$. This nature of the ship tracks is maintained even when they extend to areas that are completely cloud 


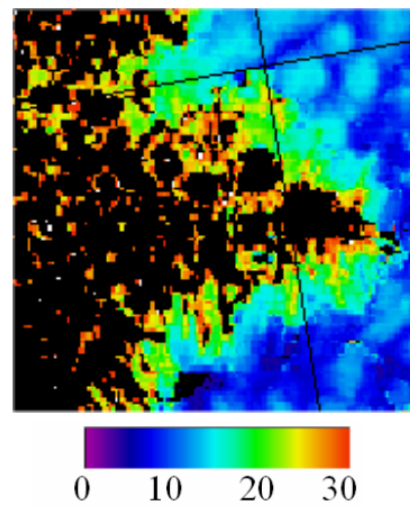

Cloud drop effective radius $[\mu \mathrm{m}]$

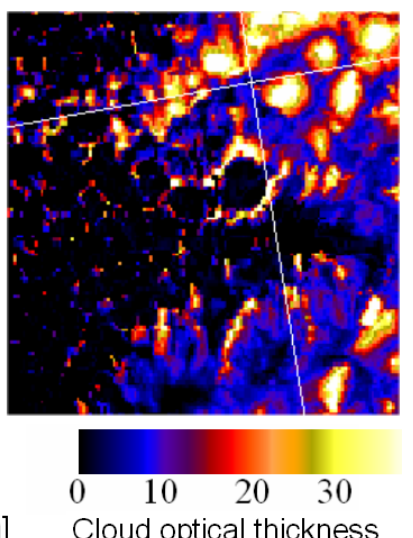

Fig. 5. The cloud drop effective radius and cloud optical thickness from the center of the scene shown in Figs. 2 and 3. Note that the largest effective radii occur at the center of the optically thick clouds, both in the closed and open cells. The cloud drop effective radii are smaller than the $15 \mu \mathrm{m}$ drizzle threshold in the closed cells and greater than $20 \mu \mathrm{m}$ in the optically thickest clouds composing the open cells.

free, and demonstrate by this that these areas became cloudfree due to lack of $\mathrm{CCN}$, apparently due to a runaway rainout process that occurred there.

The retrieved effective radius can be overestimated in thin and broken clouds (Coakley et al., 2005), but it becomes quite accurate in clouds with optical thickness $>8$ in the visible (Rosenfeld et al., 2004). Comparing the MODIS products of cloud drop effective radius and cloud optical depth for the case study here (Fig. 5) shows that the optically thickest clouds have the largest DER, both in the closed and in the open cell regimes, and it is the DER in these optically thick clouds that shows the large contrast between open and closed cells.

The drier atmosphere above the MBL likely sharpens the bistability. Entrainment of drier air from above the MBL reduces the cloud water and so suppresses drizzle and lowers the droplet concentration threshold below which heavy drizzle can occur and deplete the cloud water (Ackerman et al., 2004). Once the cloud cover is broken, drier air aloft will lead to stronger radiative cooling of the MBL by thermal emission from the water vapor and hence a faster reversal into open cellular convection. The clouds are already drizzling quite heavily due to the lower concentrations of cloud droplets required for the transition from closed to open cells with drier air above the MBL. This will lead to a faster runaway super-clean state, which is maintained by the suppressed convection and hence minimal entrainment of $\mathrm{CCN}$ from the FT.

The mechanism proposed here dictates that the natural progression of events would be from closed to open cells, unless heavy doses of aerosols are injected into the MBL, as occurs in the case of ship tracks. In agreement with this, Wood and Hartmann (2006) stated that "qualitative examination of geostationary satellite imagery suggests that a mesoscale cellular convection usually transitions from closed to open. This change often takes the form of small pockets of open cells forming over a few hours within regions of extensive closed cells, which then grow to become extensive areas of open mesoscale cellular convection." This observation is supported by an image sequence of 6 days and nights using the multispectral capabilities of the METOSAT- 8 geostationary satellite. This sequence uses a microphysical rendition of the clouds for both daylight (Rosenfeld and Lensky, 1998) and night time (developed by the first author and first applied here in a journal publication), showing the evolution of marine stratocumulus with pockets of open cells over the SE Atlantic Ocean (Figs. 6 and 7). The movies show that the snap shot images shown in Figs. 2-5 can also be viewed as describing the time evolution from closed to open cells and occasionally further to the super clean cloud free areas.

The self maintenance nature of the open cells is evident upon tracking their time evolution. The movies in Figs. 6 and 7 show long living pockets of open cells that are tracked for up to four days while gradually expanding. Some of the pockets of open cells seem to struggle through ship tracks that cut through them. The pockets of open cells in this sequence migrate with the trade winds towards the ITCZ, where the cloud system in which they are imbedded is eliminated at the confluence with the north hemispheric air mass.

The simulation of the conversion from closed to open Benard cells remains yet an unsolved challenge. However, Mechem and Kogan (2003) were able to simulate the transition between continuous layer clouds into a broken cloud field when allowing drizzle to form in their simulated clouds. In their model, the unbroken stratocumulus, driven energetically by strong cloud-top cooling and to a lesser extent, surface fluxes, is kept well mixed within the MBL, with thermodynamic quantities remaining nearly well mixed. In the drizzling experiment, on the other hand, drizzle evaporating in the sub-cloud layer changes the character of the boundary layer sufficiently to allow a slight pooling of high static stability air just above the surface. The instability associated with this slight CAPE within the MBL is subsequently realized through resolved updrafts, which are associated with the strongest drizzle production. Compensating downdrafts seem to be able to trigger new upward vertical motion on their periphery, resulting in the initiation of cumulus ensembles in adjacent regions. This transition occurs within $6 \mathrm{~h}$ in the model. The presence of drizzle is vital for this transition to occur in the model.

\section{Possible aerosol role of converting marine stratocu- mulus to trade wind cumulus}

The proposed hypothesis of precipitation induced regime change can potentially explain the breaking of marine Sc 


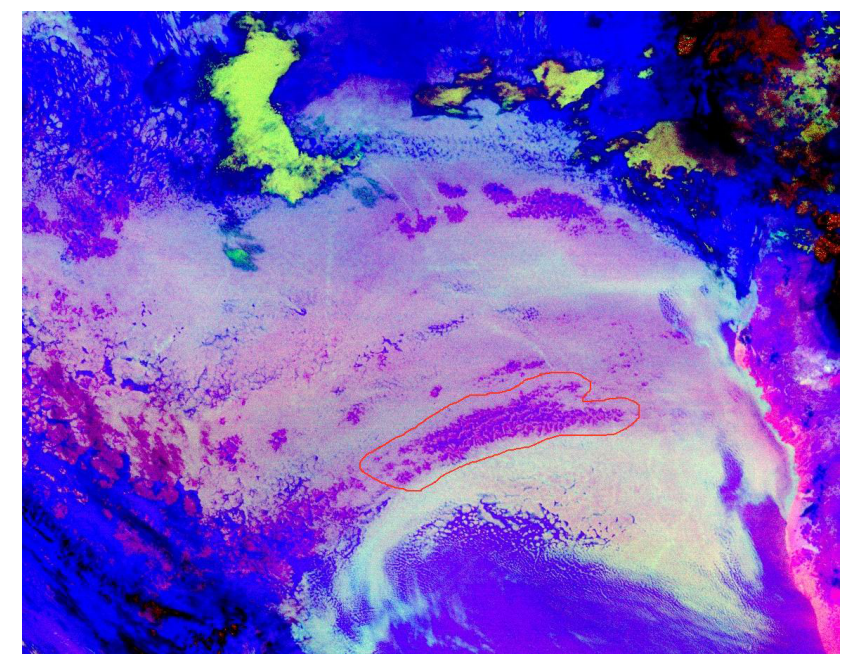

Fig. 6. Pockets of open cells (the purple areas; the largest is enclosed by a red line) in a deck of marine stratocumulus with ship tracks in the southeast Atlantic, as seen by the geostationary satellite METEOSAT-8, on 27 November 2005, 04:00 UT. The image is at the satellite projection and covers $\sim 4^{\circ} \mathrm{S}-32^{\circ} \mathrm{S}$ and $18^{\circ} \mathrm{W}-18^{\circ} \mathrm{E}$. Namibia coast is seen at the lower right. A six-day and night animation of such hourly images is available here, for 24 November 04:00-30 November 00:00 UT (http://www.atmos-chem-phys.net/ 6/2503/2006/acp-6-2503-2006-supplement.zip, supplement figure $6)$.The images are Red Green Blue composites where during nighttime the red is modulated by $12.0-10.8 \mu \mathrm{m}$ brightness temperature (BT) difference, Green is $10.8-3.9 \mu \mathrm{m}$ BT difference, and blue is $10.8 \mu \mathrm{m} \mathrm{BT}$. During daytime Red is visible reflectance, green is $3.9 \mu \mathrm{m}$ solar reflectance, and blue is $10.8 \mu \mathrm{m} \mathrm{BT}$. The transitions between day and night are evident by the poor quality of the dusk images. The open cells eventually disappear upon confluence with what appears to be polluted north hemispheric air, as evident by the bright color of these clouds which reflects their small droplet size. The bright yellow areas are elevated layer water clouds. The dark red and black spots are ice clouds.

into the trade winds $\mathrm{Cu}$. The subtropical inversion gradually rises and the MBL thickens westward and towards the ITCZ, and the layer clouds break at some point into the trade wind cumulus clouds (Fig. 8). This breaking can occur due to movement of the air mass over warmer waters and dominance of the low level warming of the MBL on the cloud top radiative cooling. It can also happen due to the greater tendency of the MBL clouds to increase their precipitation intensity as they grow deeper (Fig. 9). It is expected that at some point in the deepening the cloud drop coalescence would reach a point where the precipitation rate would be sufficient to cause the transition change from closed to open convection, if it was not broken already due to other causes such as wind shear, warming of the sea surface temperature, or enhanced dry entrainment from above. However, such entrainment is not likely to break the layer clouds, as suggested by Gerber et al. (1996).

The further enhancement of the precipitation with the

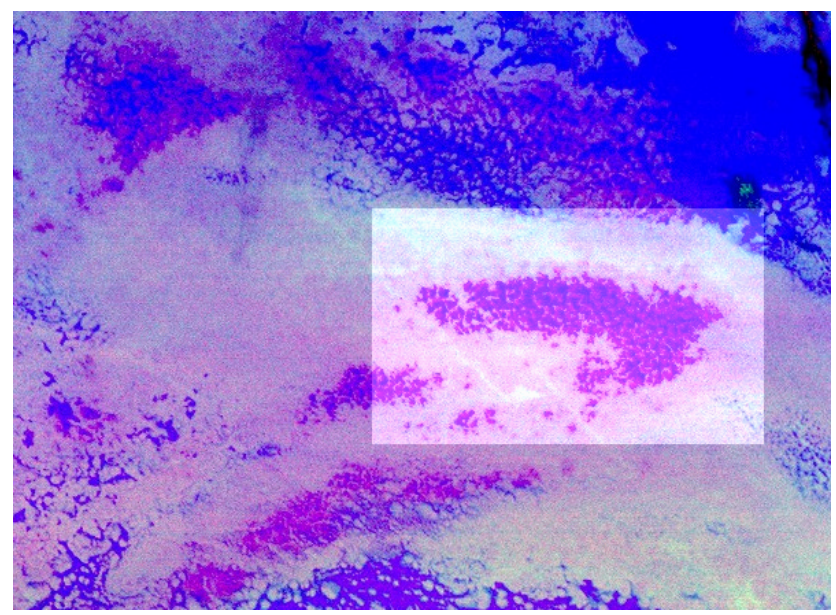

Fig. 7. The same movie as in Fig. 6, but with one area of open cells being enhanced as shown in the figure and tracked with time (http://www.atmos-chem-phys.net/6/2503/2006/ acp-6-2503-2006-supplement.zip, supplement figure 7). Certain features of open cells can be tracked for four days, where the self maintained dynamics and their interactions with the ship tracks are evident. The self maintenance of the open cells is further evident by the observation that the marine stratus undergoes considerable diurnal change of maximum cover during early morning and minimal cover late in the day, while the structure of the open cells appears to respond much less to the diurnal cycle. The image shown is from 27 November 2005 22:00 UT, with a magnification by a factor of about 2 compared to the scale of Fig. 6.

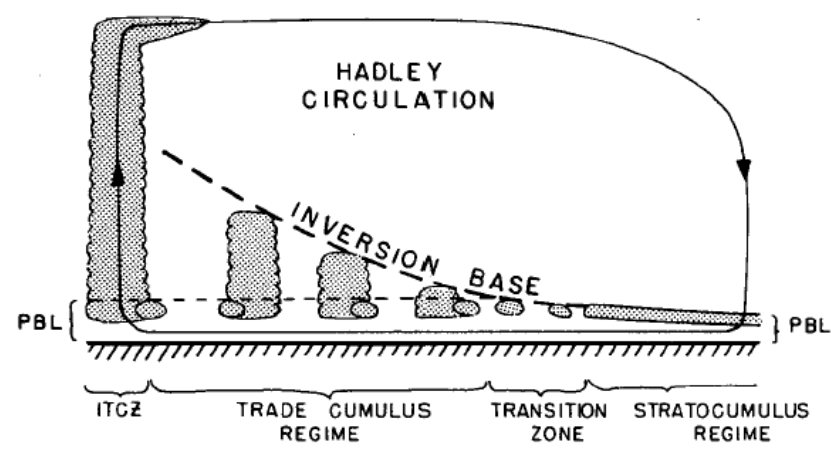

Fig. 8. Transition to trade $\mathrm{Cu}$ : The breaking of marine stratocumulus into the trade wind cumulus with the deepening of the MBL (from Randall, 1980a): Does it occur when the clouds become sufficiently deep for precipitation? If so, aerosols would affect the transition front.

deepening of the convective clouds as the MBL thickens towards the ITCZ is associated with further decreasing of the cloud fraction down to 0.3 at a MBL depth $=2000 \mathrm{~m}$, and remains at that value of CF for greater depths (Fig. 18 of Wood and Hartmann, 2006). This is the height at which most of the small convective clouds over ocean start precipitating at intensities detectable by weather radar, i.e., $>1 \mathrm{~mm} / \mathrm{hr}$ (Battan and Braham, 1956; Johnson et al., 1999). Interestingly, 


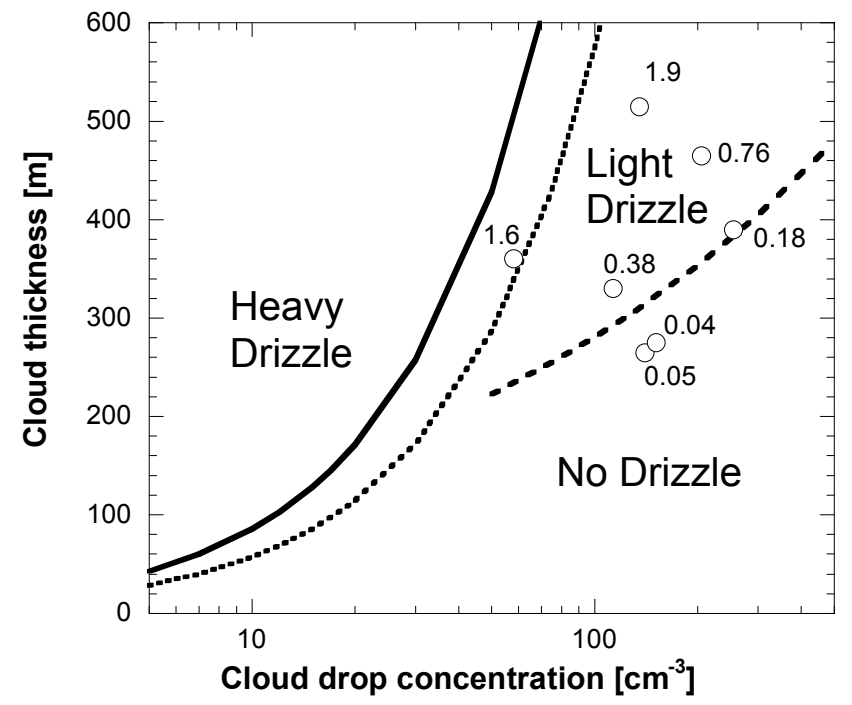

Fig. 9. Partition of the drop number concentration and cloud thickness parameter space for separating heavy drizzling marine stratocumulus where most water resides in the drizzle drops, lightly drizzling were most water resides in the cloud drops, and non drizzling clouds. The thick line occurs at cloud drop effective radius $r_{e}=16 \mu \mathrm{m}$, which was calculated after Gerber (1996) to be the minimal size for the heavy drizzle regime. The dotted line shows the location of $r_{e}=14 \mu \mathrm{m}$. The separator between no drizzle and light drizzle of $R>0.2 \mathrm{~mm}$ day $^{-1}$ is provided by the broken line based on DYCOMS-II observations (vanZanten et al., 2005). The individual points and their $\mathrm{R}$ values are posted (from Table 3 of vanZanten et al., 2005).

this is the height at which clouds over the ocean would start raining even if they are polluted, due to the effect of sea spray aerosols that restore the precipitation processes in such clouds, as shown by Rosenfeld et al. (2002).

\section{Discussion and summary}

We have proposed here a hypothesis that explains the mechanisms for maintenance and transitions between three basic states of the structure of the MBL - closed and open cellular Benard convection, and the super-clean state where clouds cannot form due to lack of CCN. It is suggested that these states are manifestations of the dynamic response of the marine $\mathrm{Sc}$ to the aerosol induced effects on precipitation. These states have internal positive feedbacks for self maintenance and sharp differentiation into these distinct states, as demonstrated by the sharp demarcation between the regimes of open and closed cells in the figures even where ship tracks are absent. The ship tracks serve to demonstrate the role of the dearth of aerosols in maintaining the dynamic structure of the MBL mediated by the cloud-aerosol-precipitation processes.
Although the proposed mechanism is still a hypothesis that remains to be validated, it is already established that the change of regimes from closed to open cells occurs abruptly at rather low aerosol concentrations. The values in which the transition occur are within $\mathrm{AOD}<0.1$, centered at the pristine background of $\mathrm{AOD}=\sim 0.06$ (Smirnov et al., 2002). The transition from open cells to the super clean cloudless state obviously occurs at extremely low aerosols concentrations. This situation provides a huge sensitivity to very small differences in aerosol amounts that can lead to a bifurcation of the state of the MBL and the respective cloud radiative forcing. The strong decrease of cloud cover at the smallest values of aerosol optical depth (see Fig. 1, especially at the upper left panel for the South Atlantic) provides some supporting evidence for the climatological importance of the processes that were shown here on the basis of a few case studies. The validation of our proposed mechanism may lead to a different approach in the model calculations of cloud-mediated aerosol forcing - i.e. so far most of the studies showed linear or logarithmic dependence between aerosols and cloud properties. Here we suggest mechanism that reacts more like a step function between almost $100 \%$ cloud fraction (close cells) to less than $40 \%$ in case of open cells, and then near zero cloud fraction for the super-clean areas.

This apparent huge sensitivity of the cloud cover provides a mechanism for large response of Earth global temperature to very small changes in the aerosols in the MBL. Such changes can be anthropogenic or oceanic biogenic such as due to fertilization of the ocean with nutrients that causes greater production of aerosols from the enhanced gaseous biogenic emissions (Wingenter et al., 2004). If the suggested modulation of global temperature by cosmic rays (Carlslaw et al., 2002) is real, the most likely mechanism to drive it is by cosmic rays changing super clean cloudless areas into open cells, and perhaps further changing open cells to closed cells. The great sensitivity of the regime transitions to very small changes in $\mathrm{CCN}$ concentrations opens the possibility that even the changes of few $\mathrm{CCN}$ generated by variability in cosmic rays might make a climatic significant difference in the cloud cover of the pristine MBL.

Acknowledgements. The paper was partially supported by the Israeli Ministry of Science and the Israeli Science Foundation.

Edited by: W. Conant

\section{References}

Ackerman, A. S., Kirkpatrick, M. P., Stevense, D. A., and Toon, O. B.: The impact of humidity above stratiform clouds on indirect aerosol climate forcing, Nature, 432, 1014-1017, 2004.

Ackerman, A. S., Toon, O. B., and Hobbs, P. V.: Dissipation of marine stratiform clouds and collapse of the marine boundary layer due to the depletion of cloud condensation nuclei by clouds, Science, 262, 226-229, 1993. 
Ackerman, A. S., Toon, O. B., and Hobbs, P. V.: Reassessing the dependence of cloud condensation nucleus concentration on formation rate, Nature, 367, 445-447, 1994.

Agee, E. M., Chen, T. S., and Dowell, K. E.: A review of mesoscale cellular convection, Bull. Amer. Meteorol. Soc., 54, 1004-1012, 1973.

Atkinson, B. W. and Zhang, J. W.: Mesoscale shallow convection in the atmosphere. Rev. Geophys., 34, 403-431, 1996.

Baker, M. B. and Charlson, R. J.: Bistability of CCN concentrations and thermodynamics in the cloud-topped boundary layer, Nature, 345, 142-145, 1990.

Battan, L. J. and Braham Jr., R. R.: A study of convective precipitation based on cloud and radar observations, J. Meteor., 13, 587-591, 1956.

Carlslaw, K. S., Harrison, R. G., and Kirkby, J.: Cosmic rays, clouds, and climate, Science, 298, 1732-1737, 2002.

Coakley, J. A., Bernstein, R. L., and Durkee, P. A.: Effect of shipstack effluents on cloud reflectivity, Science, 237, 1020-1022, 1987.

Coakley Jr., J. A. and Walsh, C. D.: Limits to the aerosol indirect radiative effect derived from observations of ship tracks, J. Atmos. Sci., 59, 668-680, 2002.

Feingold, G. F., Stevens, B., Cotton, W. R., and Frish, A. S.: The relationship between drop in-cloud residence time and drizzle production in numerically simulated stratocumulus clouds, J. Atmos. Sci., 53, 1108-1122, 1996.

Gerber H.: Microphysics of marine stratocumulus clouds with two drizzle modes, J. Atmos. Sci., 53, 1649-1662, 1996.

Gunn, R. and Phillips, B. B.: An experimental investigation of the effect of air pollution on the initiation of rain, J. Meteorol., 14, 272-280, 1957.

Hegg, D. A.: Dependence of marine stratocumulus formation on aerosols, Geophys. Res. Let., 26(10), 1429-1432, 1999.

Jiang, H., Feingold, G., and Cotton, W. R.: A modeling study of entrainment of cloud condensation nuclei into the marine boundary layer during ASTEX, J. Geophys. Res., 107(D24), 4813, doi:10.1029/2001JD001502, 2002.

Johnson, R. H., Rickenbach, T. M., Rutledge, S. A., Ciesielski, P. E., Schubert, W. H.: Trimodal characteristics of tropical convection, J. Clim., 12, 2397-2418, 1999.

Kaufman, Y. J., Koren, I., Remer, L. A., Rosenfeld, D., and Rudich, Y.: Smoke, Dust and Pollution Aerosol Clouding the Atlantic Atmosphere, Proceedings of the National Academy of Sciences, 102, 11 207-11 212, 2005.

Mechem, D. B. and Kogan, Y. L.: Simulating the transition from drizzling marine stratocumulus to boundary layer cumulus with a mesoscale model, Mon. Wea. Rev., 131, 2342-2360, 2003.

Paluch, I. R. and Lenschow, D. H.: Stratiform cloud fraction in the marine boundary layer, J. Atmos. Sci., 48, 2141-2158, 1991.

Petters, M. D., Snider J. R., Stevens, B., Vali, G., Faloona, I., and Russell, L.: Accumulation mode aerosol, pockets of open cells, and particle nucleation in the remote subtropical Pacific marine boundary layer, J. Geophys. Res., 111, D02206, doi:10.1029/2004JD005694, 2006.
Pincus, R. and Baker, M. B.: Effect of precipitation on the albedo susceptibility of clouds in the marine boundary-layer, Nature, 372, 250-252, 1994.

Platnick, S. P., Durkee, A., Nielsen, K., Taylor, J. P., Tsay, S.-C., King, M. D., Ferek, R. J., Hobbs, P. V., and Rottman, J. W.: The role of background cloud microphysics in the radiative formation of ship tracks, J. Atmos. Sci., 57, 2607-2624, 2000.

Randall, D. A.: Conditional instability of the first kind upsidedown, J. Atmos. Sci., 37, 125-130, 1980a.

Randall, D. A.: Conditional Entrainment into a stratocumulus layer with distributed radiative cooling, J. Atmos. Sci., 37, 148-159, $1980 b$.

Rosenfeld, D., Cattani, E., Melani, S., and Levizzani, V.: Considerations on daylight operation of $1.6 \mu \mathrm{m}$ vs. $3.7 \mu \mathrm{m}$ channel on NOAA and METOP Satellites, Bull. Amer. Meteorol. Soc., 85, 873-881, 2004.

Rosenfeld, D., Lahav, R., Khain, A. P., and Pinsky, M.: The role of sea-spray in cleansing air pollution over ocean via cloud processes, Science, 297, 1667-1670, 2002.

Rosenfeld, D. and Lensky, I. M.: Satellite-based insights into precipitation formation processes in continental and maritime convective clouds, Bull. Amer. Meteorol. Soc., 79, 2457-2476, 1998.

Sekiguchi, M., Nakajima, T., Suzuki, K., Kawamoto, K., Higurashi, A., Rosenfeld, D., Sano, I., and Mukai, S.: A study of the direct and indirect effects of aerosols using global satellite datasets of aerosol and cloud parameters, J. Geophys. Res., 108(D22), 4699, doi:10.1029/2002JD003359, 2003.

Smirnov, A., Holben, B. N., Kaufman, Y. J., Dubovik, O., Eck, T. F., Slutsker, I., Pietras, C., and Halthore, R. N.: Optical Properties of Atmospheric Aerosol in Maritime Environments, J. Atmos. Sci., 59, 501-523, 2002.

Stevens, B., Vali, G., Comstock, K., van Zanten, M. C., Austin, P. H., Bretherton C. S., and Lenschow, D. H.: Pockets of Open Cells (POCs) and Drizzle in Marine Stratocumulus, Bull. Amer. Meteorol. Soc., 86, 51-57, 2005.

Twomey, S.: The influence of pollution on the shortwave albedo of clouds, J. Atmos. Sci., 34, 1149-1154, 1977.

Wingenter, O. W., Haase, K. B., Strutton, P., Friederich, G., Meinardi, S., Blake, D. R., and Rowland, F. S.: Changing concentrations of $\mathrm{CO}, \mathrm{CH}_{4}, \mathrm{C}_{5} \mathrm{H}_{8}, \mathrm{CH}_{3} \mathrm{Br}, \mathrm{CH}_{3} \mathrm{I}$, and dimethyl sulfide during the Southern Ocean Iron Enrichment Experiments, Proc. Nat. Acad. Sci., 101(23), 8537-8541, 2004.

Wood, R. and Hartmann, D. L.: Spatial variability of liquid water path in marine low cloud: The importance of mesoscale cellular convection, J. Clim., 19, 1748-1764, 2006.

VanZanten, M. C., Stevens, B., Vali, G., and Lenschow, D. H.: Observations in nocturnal marine stratocumulus, J. Atmos. Sci., 62, 88-106, 2005. 